\title{
How Wisdom Can Help Solve Global Problems
}

Nicholas Maxwell

Science and Technology Studies, University College London

Email: nicholas.maxwell@ucl.ac.uk

Published in Applying Wisdom to Contemporary World Problems, eds., R. Sternberg, H.

Nusbaum and J. Glueck, PalgraveMacmillan, London, chapter 13.

\section{Abstract}

Two great problems of learning confront humanity: learning about the nature of the universe and about ourselves and other living things as a part of the universe, and learning how to become civilized. The first problem was solved, in essence, in the 17th century, with the creation of modern science. But the second problem has not yet been solved. Solving the first problem without also solving the second puts us in a situation of great danger. All our current global problems have arisen as a result. What we need to do, in response to this unprecedented crisis, is learn from our solution to the first problem how to solve the second. This was the basic idea of the 18th century Enlightenment. Unfortunately, in carrying out this programme, the Enlightenment made three blunders, and it is this defective version of the Enlightenment programme, inherited from the past, that is still built into the institutional/intellectual structure of academic inquiry in the 21 st century. In order to solve the second great problem of learning we need to correct the three blunders of the traditional Enlightenment. This involves changing the nature of social inquiry, so that social science becomes social methodology or social philosophy, concerned to help us build into social life the progress-achieving methods of aim-oriented rationality, arrived at by generalizing the progress-achieving methods of science. It also involves, more generally, bringing about a revolution in the nature of academic inquiry as a whole, so that it takes up its proper task of helping humanity learn how to become wiser by increasingly cooperatively rational means. The scientific task of improving knowledge and understanding of nature becomes a part of the broader task of improving global wisdom. The outcome would be what we so urgently need: a kind of inquiry rationally designed and devoted to helping us make progress towards a genuinely civilized world. We would succeed in doing what the Enlightenment tried but failed to do: learn from scientific progress how to go about making social progress towards as good a world as possible.

\section{Our Global Problems}

Our future looks grim. We are confronted by grave global problems which show every sign of intensifying in the future. Millions, possibly billions, of people may suffer and die prematurely from disaster as a result. ${ }^{1}$

In this chapter I argue that the key thing we need to do to save humanity from disaster is bring about a revolution in academia so that the basic aim becomes wisdom, and not just knowledge.

But could more wisdom really help? Before I tackle that problem, let me first indicate in a little more detail, the nature and scale of the global problems that confront us.

There is the problem of rapid population growth. A few years ago it was thought that the world's population might level off at something like ten billion by the middle of the century. Now it is thought there may be as many as eleven billion people by the end of the century. ${ }^{2}$ There is the problem of habitat destruction and increasingly rapid extinction of species. We are living in a period of mass extinctions, only this time the cause is us. There is the problem of vast inequalities of wealth and power around the globe - inequalities that have in some respects increased in the last few decades: see, for example, Piketty (2014); Wilkinson and Pickett (2010) . There is the problem of the spread of modern armaments, conventional, 
chemical, biological, nuclear. The mere existence of nuclear weapons held ready for launching is a menace: sooner or later they will be unleashed, whether as a result of international conflict, accident, malfunctioning equipment, or hacking. And on top of that, there is our proclivity for war, our record of war, and the increasingly lethal character of war: something like twelve million people killed in wars in the nineteenth century, around one hundred million in the twentieth century - and we have not been doing too well so far in this century. There is the problem of pollution of earth, sea, and air. And most serious of all, there are the impending threats of climate change. As the population goes up way beyond what one imagines the earth can sustain, the capacity of the earth to support and feed people goes down as climate change decreases habitable land as a result of drought and flooding; food production is threatened, people attempt to migrate en masse, and all the conditions likely to provoke war and devastation come to prevail.

\section{What is Wisdom?}

How might greater wisdom help solve these grave global problems? Before I can say anything about that question, I first need to indicate what I take wisdom to be. I can do no better than quote from a book of mine called From Knowledge to Wisdom, even more relevant today than when it was first published, long ago in 1984.

Wisdom [is] understood here [to be] the desire, the active endeavour, and the capacity to discover and achieve what is desirable and of value in life, both for oneself and for others. Wisdom includes knowledge and understanding but goes beyond them in also including: the desire and active striving for what is of value, the ability to see what is of value, actually and potentially, in the circumstances of life, the ability to experience value, the capacity to help realize what is of value for oneself and others, the capacity to help solve those problems of living that arise in connection with attempts to realize what is of value, the capacity to use and develop knowledge, technology and understanding as needed for the realization of value. ${ }^{3}$ Wisdom, like knowledge, can be conceived of, not only in personal terms, but also in institutional or social terms. (From Knowledge to Wisdom, chapter 4). ${ }^{4}$

\section{Wise Policies to Save the World}

Let us suppose that, magically, one night, the world's population acquires wisdom in this sense. Or, to make it fractionally more plausible, let us suppose that $60 \%$ of humanity acquires wisdom in this sense, while the remaining $40 \%$ continue with as much, or as little, wisdom as they had before.

Abruptly, $60 \%$ of humanity has acquired the desire, the active endeavour, and the capacity to discover and achieve what is desirable and of value in life, both for themselves and for others. This suddenly acquired desire, capacity and endeavour will presumably, for each person, have all sorts of desirable, valuable consequences specifically for that person, and for those the person loves and knows. There will be limits to these good consequences, of course. Some suffering, some bad things, cannot be got rid of, however wise we may be. If you are dying of cancer, you will die, whether you are wise or not - although, if you are wise, you may be able to make better use of the time that is left to you. If you live in conditions of unrelenting poverty, imprisonment, or enslavement, acquiring wisdom may not be of much help. Wisdom can only help when actions are possible which, if performed, lead to the realization of what is desirable and of value, and it requires wisdom to discover what these actions are, and perhaps to perform them in the way that is required.

But in addition to purely personal benefits that might flow from the abrupt acquisition of wisdom, there would be public benefits too. Our $60 \%$ of humanity, on acquiring wisdom, 
would see all too clearly the desirability, the value, of progressively resolving the grave global problems that confront us. They would appreciate that retaining nuclear weapons ready to be unleashed at the touch of a button in itself threatens the future of humanity. They would appreciate that population growth, destruction of the natural world, decimation of living things, extinction of species, war, gross inequality, pollution of earth, sea, and air, and impending global warming are all disastrous. They would appreciate that everything possible must be done to put a stop to these disastrous outcomes.

Why can we be sure that our $60 \%$ of wise humanity would appreciate all this? Because, being wise, they hold the future welfare of their loved ones, children, friends, and fellow citizens, fellow human beings to be profoundly desirable and of value, and they would have no difficulty in appreciating that all this is under threat if nothing is done to solve these global problems. In order to achieve what is supremely desirable and of value for the future, these global problems must be solved!

This point may be conceded. After all, most reasonably educated people today appreciate that we must solve these global problems if we are to avoid heading toward disaster. Not all educated people appreciate this, but most do, with the modicum of wisdom that the educated of the world possesses. So it is not unreasonable to conclude that our wise $60 \%$ of humanity will rapidly come to the same conclusion.

The crucial question is, then: But what could the wise $60 \%$ actually do to solve these global problems? That is the question that we must try to answer.

My view is that most of the $60 \%$ would agree that the key to solving our global problems is to get governments to implement appropriate policies. What would these policies be? They would include the following.

1. Proper funding to make birth control freely available to everyone on the planet.

2. Agreement among the nuclear powers - USA, China, Russia, UK, France, India, Pakistan, Israel and North Korea - to eliminate progressively all nuclear weapons, and at the same time establish an international body with powers to inspect any nuclear facility anywhere in the world to ensure nuclear weapons are not being developed in secret.

3. Governments around the world put on a war footing to take action to stop climate change.

4. Adoption by governments around the world of a policy to tax $\mathrm{CO}_{2}$ emissions, primarily the use of oil and coal, this tax being such that it increases at a steady, announced rate, year on year. The rationale behind this tax is that it would discourage use of oil and coal, and would encourage development of alternative methods of energy production.

5. At the same time, a crash programme by governments around the world to replace energy production by means of coal, oil and gas, with sustainable technology of energyproduction: solar panels, wind farms, hydropower, wave power, tidal power, nuclear power. World-wide $\mathrm{CO}_{2}$ emissions due to electricity production to be halved in ten years, and brought to zero in 20 years.

6. The creation of vast solar panel power stations in desert regions such as the Sahara, to produce electricity for heavily populated regions, local regions benefiting from the sale of electricity.

7. A crash programme to convert transport so that, instead of being fueled by petrol and oil, it is fueled by electricity and hydrogen (the presumption being that 4 to 6 are being implemented simultaneously). World-wide $\mathrm{CO}_{2}$ emissions due to transport to be halved in ten years and brought to zero in 20 years (excluding air traffic).

8. Active collaboration of democratic nations to do what can be done to encourage undemocratic nations to become democratic. 
9. Creation of democratic world government.

10. Protection of natural habitats, such as tropical rain forests, and adoption of policies to put a stop to species extinctions, and the loss of wild life.

\section{Wisdom Politics}

But how would the wise $60 \%$ of humanity succeed in getting governments around the world to implement these policies? Much depends on whether we are considering a democratic or a dictatorial state. Let's consider the case of a democracy first.

If $60 \%$ of the electorate clamoured for their government to implement the above policies, 1 to 10 , sooner or later, I believe, the democratically elected government would indeed come to put these policies into practice. The $60 \%$ would need to create a "global problem solving" (GPS) campaign. Public figures, the media, social media, would need to be galvanized to promote the campaign. Members of the $60 \%$ would have to be prepared to desert their political party of choice if it proved recalcitrant in agreeing to adopt GPS policies. It would need to be made clear to political parties that failure to support GPS policies would be electoral suicide. And once a government is in place that declares its determination to put GPS policies into practice, every action of the government would need to be closely watched by the $60 \%$ - or by its representatives. It is to be expected that big and powerful bodies with interests at stake, oil and logging companies, car manufactures, and the military, for example, would lobby governments to perform only window dressing, so that it looks as if GPS policies are being implemented when actually nothing very much is being done. There would be set-backs, deceptions and betrayals, all of which would have to be pounced upon, highlighted, and punished. But our $60 \%$ are wise; that is, they have the desire, the active endeavour, and above all the capacity to achieve what is of value - in this case what is of value being the implementation of GPS policies by the government - policies designed to save the world from disaster. Our wise $60 \%$ would be able to do what needs to be done (a) to get a government committed to implementing GPS policies, and (b) to get the government actually to do what it is committed to doing.

So much for those nations that have democracy, free speech, a free press, the rule of law. What, though, of nations governed by dictators - perhaps with a deceptive patina of democracy, as in Egypt or Russia at the time of writing (2018)?

The Economist Intelligence Unit's Democracy Index of 2016 finds that there are only 19 "full" democracies in the world. There are 57 "flawed" democracies, 40 "hybrid" regimes, and 51 "authoritarian" regimes. ${ }^{5}$ It can be assumed that it would be very much more difficult to establish a government committed to implementing GPS policies in a flawed democracy, and all but impossible to do it in a hybrid or authoritarian regime. It seems that toppling authoritarian regimes and transforming hybrid regimes and flawed democracies into full democracies may be a very time consuming first step toward establishing governments committed to pursuing GPS policies.

In some respects, this is too simplistic. China is certainly not democratic. Nevertheless, China's government is well-aware of the dangers of climate change - much more aware than Donald Trump's USA government, again at the time of writing (2018). China at present emits more $\mathrm{CO}_{2}$ than any other nation, but in terms of $\mathrm{CO}_{2}$ emissions per person, a number of nations emit more $\mathrm{CO}_{2}$, including the USA, Canada, and the UK. Dictatorial regimes, nevertheless, pose a very serious problem. It seems unlikely that Putin's Russia, Assad's Syria, or Kim Jong-un's North Korea will be keen to do what they need to do to help solve global problems - especially as that would involve handing power over to democratically elected governments. Nations that implement policies designed to solve global problems in desirable ways can impose trade sanctions on nations that do not, but the result of that tends to be more suffering for the people of the sanctioned nations - people already suffering in 
living in a nation governed by a dictator. It may be more just and effective to target sanctions against those who hold power or are cronies of those in power. What to do about undemocratic nations, and nations that refuse to implement GPS policies, must be a fundamental problem for democratic nations, and nations that do put GPS policies into practice.

Not only are there recalcitrant nations to contend with; there are recalcitrant conflicts, such as the civil war in Syria, the conflict between Israel and the Palestinians, the situation in Afghanistan, Yemen, and in the Ukraine (again in 2018). It is possible that democratic nations will need to create an international body, open only to democratic nations, with power to enforce cessation of hostilities and gradual resolution of conflicts, so that the international democratic community has the capacity to bring about resolution of conflicts, both within and between nations.

Even if $60 \%$ of humanity miraculously acquired wisdom overnight, there would still be a long, hard struggle to get wisdom into world politics, industry, economics, finance, agriculture, law, the military, media, the social and cultural fabric of life. There would be no instantaneous transition to a wise world. But nor would our $60 \%$ of humanity abruptly acquiring wisdom make no difference at all. This constituency of the wise would be able to change for the better what goes on in countless social contexts, and above all in the context of politics and government.

The crux of the matter is simply this: How can $60 \%$ of humanity acquire the necessary wisdom to have the necessary impact on world affairs?

My answer to that question is one that $\mathrm{I}$ have been trying to get into the public domain for over 40 years. We urgently need to transform our institutions of learning, our universities and schools. We need a new kind of academic inquiry which takes, as its basic intellectual aim, not just to acquire knowledge, but rather to seek and promote social wisdom. This academic revolution is needed in the interests of reason, and in the interests of humanity.

This is an argument that I have been expounding, in and out of print, as I say for over 40 years, ${ }^{6}$ so here I will be brief.

\section{The Damaging Irrationality of Knowledge-Inquiry}

Academic inquiry as it mostly exists at present in universities around the world is an intellectual and humanitarian disaster when viewed from the standpoint of helping to promote human welfare. Academia suffers from profoundly damaging, structural irrationality. In giving intellectual priority to the pursuit of knowledge, academia is so devastatingly irrational that it violates three of the four most elementary rules of rational problem solving conceivable.

In what follows I consider two conceptions of inquiry, two kinds of inquiry, that I call knowledge-inquiry and wisdom-inquiry. Both hold that the basic social or humanitarian aim of inquiry is to help promote human welfare by intellectual, technological, and educational means. But the intellectual aims and methods of the two conceptions of inquiry are very, very different.

Knowledge-inquiry holds that the proper, basic intellectual aim of inquiry is knowledge. First knowledge and technological know-how are to be acquired; then, once acquired, they can be applied to help solve social problems, and thus help achieve the social aims of inquiry. As far as the intellectual domain of inquiry is concerned, only those factors relevant to the acquisition, assessment, and dissemination of factual knowledge are allowed entrance: observational and experimental results, valid arguments, theories, facts, logic. Everything else must be excluded: expressions of feelings, views about values, ideals and objectives, cries of pain, emotional reports about human suffering. All this must be excluded so that 
inquiry may obtain what can alone be of human value, namely: objective, factual knowledge. Values must be excluded so that what is of value - objective knowledge - may be obtained.

Science operates an even more severe censorship system. In order to enter the intellectual domain of science, an idea must be, not just factual, but empirically testable or, as Karl Popper would put it, empirically falsifiable. Everything unfalsifiable must be excluded from science.

Knowledge-inquiry is what we have inherited from the past. It was once upon a time - in the 1950s perhaps - rather more dominant than it is today. Nevertheless, knowledge-inquiry still dominates academia. It determines what the aims and methods of academic work should be. It exercises a profound influence over research, criteria for publication, what counts as a contribution to academic thought, academic promotions, rewards and prizes, education, the way diverse disciplines are developed and related to one another, the way academia is related to the rest of the social world. Almost every branch and aspect of academic activity is obliged to conform to the edicts of knowledge-inquiry. ${ }^{7}$

Knowledge-inquiry is, nevertheless, very seriously irrational in a structural and profoundly damaging way. It is hardly too much to say that all our current global problems have arisen in part because our institutions of learning have been dominated by this appallingly irrational conception of inquiry. ${ }^{8}$

What ought we to mean by "reason" in the present context? What we require is a conception which holds that there is some, possibly rather ill-defined, set of rules, methods or strategies such that, if implemented when we seek to solve problems or achieve aims, give us our best chances of achieving success, other things being equal. ${ }^{9}$ The rules of reason tell us what to attempt; they don't specify precisely what we should do. And they don't guarantee success. They are meta-methods, in that they assume that there is much that we can already do, many complex problems we can already solve, and they tell us how best to marshal our already solved problems in order to give ourselves the best chances of solving new problems, of realizing hitherto unobtainable aims. The rules of reason can be formulated either as rules designed to help us solve problems, or rules designed to help us attain aims. I make use of both formulations. It needs to be noted, incidentally, that all problem-solving is aimpursuing, and vice versa - except sometimes our brilliant brains may solve a multitude of problems involved in attaining an aim without our even realizing that it was necessary to solve any problem at all. A decade or so ago, it would take an artificial-intelligence device ten minutes or so of rapid problem-solving to recognize that a cup is a cup. We do it instantaneously, without even being aware we have thereby solved intricate problems of recognition.

Four absolutely basic, wholly uncontroversial rules of rational problem solving are:

(1) Articulate and seek to improve the articulation of the basic problem(s) to be solved.

(2) Propose and critically assess alternative possible solutions.

(3) When necessary, break up the basic problem to be solved into a number of specialized problems - preliminary, simpler, analogous, subordinate problems - (to be tackled in accordance with rules (1) and (2)), in an attempt to work gradually toward a solution to the basic problem to be solved.

(4) Inter-connect attempts to solve the basic problem and specialized problems, so that basic problem solving may guide, and be guided by, specialized problem solving. ${ }^{10}$

Any problem-solving endeavour which persistently violates one or other of these rules will be seriously irrational and will have its capacity to solve problems seriously degraded as a result. Academia as it exists today in universities around the world, as a result of 
implementing knowledge-inquiry, violates three of these four basic rules of reason. It is as serious as that.

Granted that academia has, as its basic aim, to help promote human welfare, the problems that academia will fundamentally be concerned with are problems of living, problems people encounter in their lives that are solved by what people do, or refrain from doing: problems of poverty, exploitation, suffering, unemployment, illness, misery, loneliness, despair. Knowledge and technology may be required to solve some of these problems, as they are in the case of such things as agriculture and medicine, but it is always what knowledge and technology enable us to do, or refrain from doing, that solves the problem of living, not the knowledge or technology in itself.

There is an additional point about the nature of the problems that academia needs to try to help solve, at the most basic level. In order to achieve what is of value in life more successfully than we do at present, we need to discover how to resolve conflicts and problems of living in more cooperatively rational ways than we do at present. There is a spectrum of ways in which conflicts can be resolved, from murder or all-out war at the violent end of the spectrum, via enslavement, threat of murder or war, threats of a less extreme kind, manipulation, bargaining, voting, to cooperative rationality at the other end of the spectrum, those involved seeking, by rational means, to arrive at that course of action which does the best justice to the interests of all those involved. A basic task for a kind of academic inquiry that seeks to help promote human welfare must be to discover how the resolution of conflicts and global problems can be moved away from the violent end of the spectrum toward the cooperatively rational end.

Taking these points into account, we can declare that academic inquiry, if it is to promote human welfare in such a way as to implement the above four rules of reason, must:-

(1) Articulate, and seek to improve the articulation of, personal, social, and global problems of living that need to be solved if the quality of human life is to be enhanced (including the global problems indicated above);

(2) Propose and critically assess alternative possible solutions - alternative possible actions, policies, political programmes, legislative proposals, ideologies, philosophies of life, especially those that promote enhanced cooperative rationality.

(3) Break up the basic problems of living into subordinate, specialized problems - in particular, specialized problems of knowledge and technology.

(4) Inter-connect basic and specialized problem solving. ${ }^{11}$

Academic inquiry today, still massively influenced by knowledge-inquiry, puts rule (3) into practice splendidly. Academia is composed of a maze of ever more specialized sub-divisions of specialized disciplines. Disastrously, academia fails to implement rules (1) and (2). There is, of course, some discussion of problems of living, including global problems, within academia. It proceeds in such disciplines as peace studies, economics, politics, international studies, climate science, and departments of law. But such discussion is not put at the heart of academia; it is not given the prominence and intellectual status it needs if it is both to influence, as well as be influenced by, more specialized research that goes on in more specialized disciplines, from mathematics and physics to technological research and studies in higher education, in accordance with rule (4). Discussion of problems of living, and what needs to be done to solve them, does not take place within academia in an intellectually fundamental way; it is pushed to the periphery, and it is that which ensures that academia violates rules (1) and (2). Having violated these two rules, academia cannot put rule (4) into practice either.

Three of the four most basic rules of rational problem solving are, as I have said, violated, in a wholesale, structural way by academic inquiry as it mostly exists today. And this is a 
direct consequence of the implementation of knowledge-inquiry. The intellectual standards of knowledge-inquiry demand that (1) discussion of problems of living, and (2) discussion of actions required to solve them, are excluded from the intellectual domain of inquiry, because (1) and (2) do not contribute to the acquisition of knowledge. Items (1) and (2) involve raising political and value issues which knowledge-inquiry holds to be inimical to the pursuit of knowledge, and thus in need of being excluded from the intellectual domain of inquiry. In so far as some discussion of problems of living does proceed within academia, academia has to struggle against the influential prohibition of such discussion by the dominant creed of knowledge-inquiry.

This gross, structural irrationality of academic inquiry is no mere formal matter. It has profoundly damaging consequences. It means academia fails to do what it most needs to do in order to help humanity resolve conflicts and problems of living in increasingly cooperatively rational ways. Failure to put rules (1) and (2) into practice means that academia fails to give priority to what it most needs to do to promote global problem-solving (GPS) policies and actions in the social world. Not only does academia fail itself to give intellectual priority to the tasks getting clearer about what our problems are and what we need to do about them; it fails too, of course, to engage with the social world to promote these tasks in the diverse contexts of politics, industry, the public, the media, international relations, development, economics, the law, finance, agriculture, the military. And, as a result of failing to put (1) and (2) into practice, academia fails to put rule (4) into practice as well; specialized academic problem solving is pursued in a way that is unrelated to sustained thinking about our most urgent global problems, and thus may develop in ways unrelated to human need.

Wisdom-inquiry arises when the rationality defects of knowledge-inquiry are put right, and all four of the most basic rules of rational problem solving are put into academic practice. The central, intellectually fundamental place in academic inquiry is given to the dual tasks of (1) articulating problems of living, including global problems, and (2) proposing and critically assessing possible solutions - possible actions - from the standpoint of their capacity, when put into practice, to resolve conflicts and problems of living in an increasingly cooperatively rational way. These intellectually fundamental tasks are carried out by social inquiry and the humanities, together with academics with backgrounds in relevant specialized disciplines, especially the natural and technological sciences. These tasks are undertaken in such a way as to influence research priorities in more specialized disciplines, and to be influenced by the results of these disciplines. Furthermore, academics engaged in these tasks are in two-way interaction with the social world, by means of the exchange of ideas, arguments, expressions of experiences, feelings, successes and failures, values and aspirations.

What really matters is the quality of our lives. Next to that, what matters is the quality of personal and social thinking guiding our actions, the quality of our lives having a great deal to do with the quality of our thinking guiding our actions. It is the quality of this thinking, influencing our personal, institutional and social lives, that really matters - how rational it is, how relevant, honest, cooperative, effective. This is the thinking that should be our fundamental concern - how cooperatively rational it is, how wise. Academic thought as a whole needs to be conceived of as a specialized aspect of our personal and social thinking in life, guiding our actions; it has the fundamental task of helping us to improve our personal and social thinking guiding our actions. In tackling specialized aspects of fundamental problems of living we face and seek to solve in life, academia needs to observe rule (4) in its relationship with the social world. There needs to be a two-way interaction between personal and social thinking - problem-solving - in life, and more specialized academic thought, academic problem-solving. I have tried to illustrate what is involved in Figure 1. 
If universities around the world repudiated knowledge-inquiry, modified academia just sufficiently to put wisdom-inquiry into academic practice whenever political circumstances

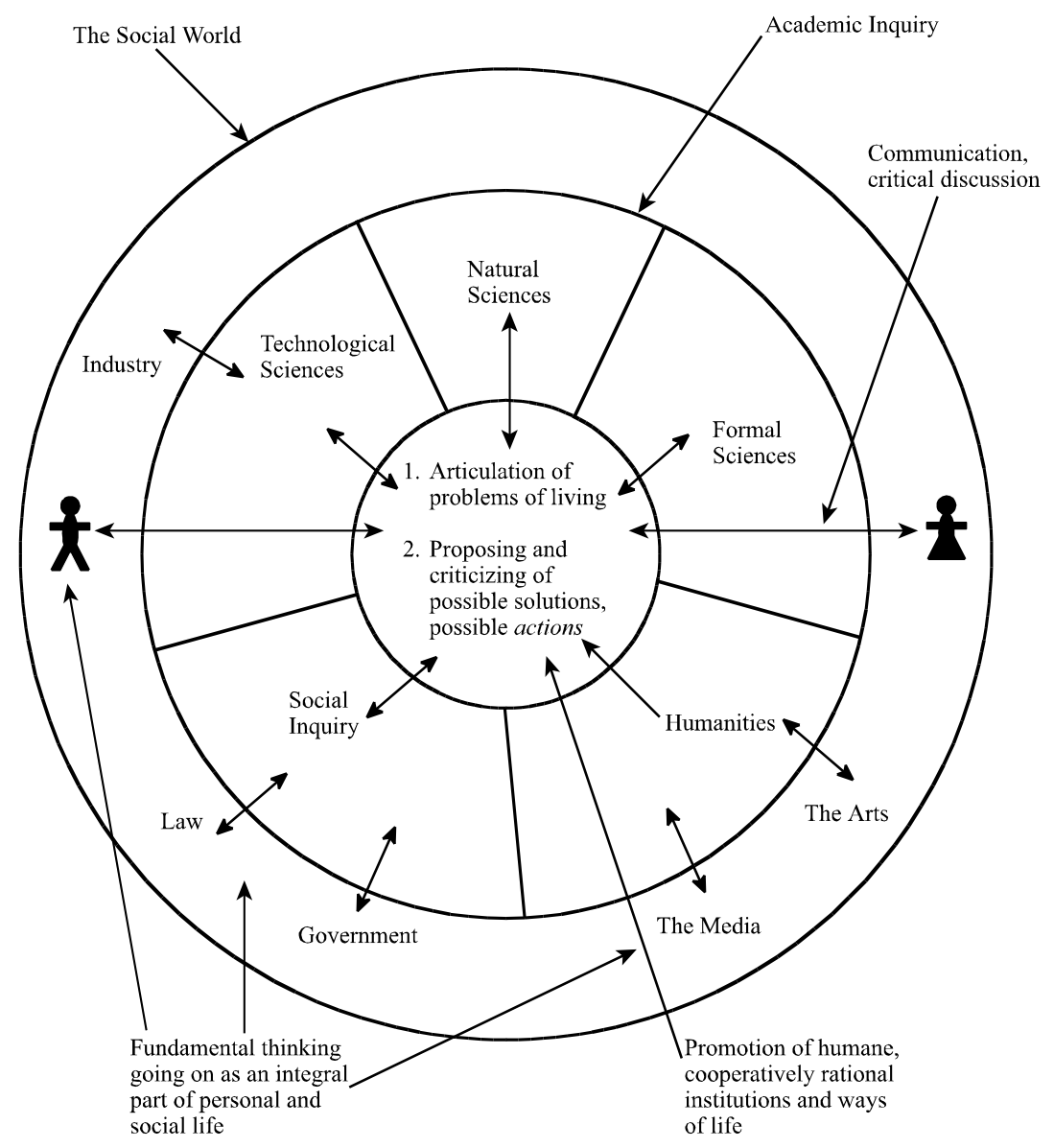

Figure 1: Wisdom-Inquiry Implementing Problem-Solving Rationality

made it possible - primarily in democratic nations - the capacity of people, institutions, and social endeavours to acquire the wisdom needed to solve global problems would be massively enhanced. Wisdom-inquiry is designed to promote social wisdom in the world in a way in which knowledge-inquiry is not.

\section{Correcting Blunders of The Enlightenment}

Academic inquiry as it exists today in universities around the world is grossly and damagingly irrational, in a structural fashion, and it is this gross irrationality of our institutions of learning that is, in part responsible for the genesis of our current grave global problems, and our inability to resolve them. That is what I have argued so far.

At once it may be asked: But how did this gross, structural irrationality of academia come about? For the answer, we have to go all the way back to the $18^{\text {th }}$ century Enlightenment especially the French Enlightenment. The philosophes - Voltaire, Diderot, Condorcet and others - had the wonderful idea that it might be possible to learn from scientific progress how to set about achieving social progress toward an Enlightened world. ${ }^{12}$ Unfortunately, in implementing this magnificent idea, the philosophes blundered. They made three serious mistakes. As a result, they sought to implement a seriously defective version of the profoundly important Enlightenment idea. It was this defective version that was developed throughout the $19^{\text {th }}$ century, by J.S. Mill, Karl Marx, Max Weber and others, and built into 
academia in the late $19^{\text {th }} /$ early $20^{\text {th }}$ centuries. The result is what we still have today: academia dominated by the profoundly irrational knowledge-inquiry.

We tend to hold that natural science is of value in two rather different ways: it is of value intellectually or culturally, in enhancing our knowledge and understanding of the world and ourselves, and it is of value practically or technologically, in enabling us to achieve desirable human goals such as health, sustenance and travel, by means of technological applications. The profound idea of the Enlightenment philosophes appeals to a third, and much neglected, way in which science can be of value. It can be of value methodologically. There is the possibility that we can learn from the astonishing intellectual progress of science how to achieve social progress towards a good, civilized, enlightened world. We may be able to get into social life progress-achieving methods generalized from the progress-achieving methods of science, thus getting into social life, something of the astonishing progress achieved by science. But in order to put this profound Enlightenment idea into practice successfully, it is absolutely essential that we get the first step right - the precise nature of scientific method which, in practice, has made it possible for natural science to achieve such astonishing progress over the decades and centuries. It is here, at this first step, that the Philosophes got things wrong, and we, today, continue to get things wrong. It is vital, then, in assessing the Enlightenment idea, that we scrutinise very carefully this first step, the precise nature of scientific method. In particular, we need to look at the basic aim and methods of natural science at its most fundamental: theoretical physics. It is here that the issues arise in their clearest form.

There are, in fact, three steps that must be got right if the profoundly significant Enlightenment idea is to be implemented properly. They are:-

1. The aim and progress-achieving methods of physics need to be correctly identified.

2. This aim and these methods need to be correctly generalized so that they become relevant and fruitfully applicable to any worthwhile human endeavour with problematic aims, whatever the aims may be, and not just applicable to the endeavour of improving knowledge.

3. The correctly generalized progress-achieving methods of physics then need to be exploited correctly in the great human endeavour of trying to make social progress toward the immensely problematic aim of creating an enlightened, wise, civilized world.

Unfortunately, the philosophes got all three steps wrong. I take these three steps in turn.

Step 1: Scientific method. The hero of the Enlightenment was Newton. And Newton claimed to have derived his law of gravitation from the phenomena by induction without appealing to metaphysics. ${ }^{13}$ Such was Newton's prestige that the philosophes took it for granted that this method summed up how science ought to proceed: derive laws and theories from phenomena by induction, and ignore metaphysics and philosophy. Improving on Newton a bit, we can say the philosophes held a version of the following view. The basic intellectual aim of physics is truth, and the basic method is to accept and reject laws and theories on the basis of their empirical success and failure. It is legitimate to take into account the simplicity, unity, or explanatory character of a theory as well, but not in such a way that nature herself is assumed to be simple, unified, or comprehensible. A central thesis of this quasi-Newtonian view - which I have called standard empiricism - is that in science, no thesis about the world can be accepted as an item of scientific knowledge independently of empirical considerations (and certainly not in violation of empirical considerations). This view - standard empiricism - is still taken for granted by scientists and non-scientists alike, including most philosophers of science. ${ }^{14}$ 
A key feature of many real-life social endeavours - above all, the endeavour to make progress towards a good, civilized, wise world - is that the actual aims of our social endeavours are profoundly problematic. There are conflicting views about what our aims and ideals ought to be, and aims we pursue have all sorts of unforeseen, undesirable consequences, and conflict with other aims we hope to realize. Almost all our current global problems have arisen because we have pursued aims that seemed desirable - economic, agricultural, industrial and medical progress - without appreciating, initially at least, the highly undesirable consequences inherent in the realization of these aims: habitat destruction, wild life loss, pollution, population growth, global warming. All this ensures that scientific method, if it is to help us achieve desirable ends when generalized and exploited in social life, must be such that it facilitates the improvement of problematic aims. But standard empiricism holds that physics has a fixed aim - truth - and fixed methods - select those theories most empirically successful. Standard empiricism is thus, on the face of it, unlikely to help us, when generalized, to improve our problematic social aims so that we achieve what is genuinely desirable and of value.

Standard empiricism is however untenable. It very seriously misrepresents the basic intellectual aim of physics, and misrepresents the methods of physics. Physics seeks, not the fixed aim of truth, but rather the profoundly problematic aim of truth presupposed to be unified or explanatory. There is a big, highly problematic metaphysical assumption inherent in the real aim of physics, and the correct methods of physics are such that they facilitate the improvement of this aim as physics proceeds. This aims-and-methods improving conception of scientific method - which I call aim-oriented empiricism - is, potentially, when generalized, of great help in enabling us to improve the aims and methods of our social endeavours: politics, industry, agriculture, social media, the law, the endeavour to make social progress towards a good world.

Why is standard empiricism untenable? The answer is that physics cannot select the theories that it does without making a very substantial metaphysical - that is, empirically untestable - assumption about the universe. That clashes with standard empiricism (which holds physics must make no assumption about the nature of the universe independently of empirical considerations).

Physics only ever accepts unified theories even though endlessly many empirically more successful disunified rivals can always be concocted to fit known phenomena even better. A unified theory is one which makes the same assertion throughout a range of phenomena to which it applies; a disunified physical theory is one which, for different phenomena, makes different assertions about how the phenomena evolve. ${ }^{15}$ In persistently accepting unified theories only, and ignoring endlessly many empirically more successful disunified rival theories that can easily be concocted, physics thereby makes a big, implicit metaphysical assumption about the universe: it is such that all disunified theories are false. Some kind of underlying unity exists in nature.

This metaphysical assumption of underlying unity is implicitly accepted, as a part of scientific knowledge, independently of empirical considerations - indeed, in a sense, in opposition to empirical considerations (which tell us that the most empirically successful theories are thoroughly disunified). This means that standard empiricism, the conception of scientific method we have inherited from the Enlightenment that is still taken for granted by scientists today, is false. ${ }^{16}$ A big metaphysical assumption about the world is implicitly accepted by physics independently of evidence, and any physical theory which clashes with it is rejected, however empirically successful it might be. The astonishing success of physics since Galileo has been achieved despite the allegiance of physicists to standard empiricism, not because of it. 
We need a new conception of scientific method to replace standard empiricism. The first step is to appreciate that the metaphysical thesis of underlying unity, implicitly accepted by physics, needs to be made explicit within physics, so that it can be critically assessed, and so that alternatives can be developed and assessed, in the hope that the specific assumption that is accepted will be improved. The second step is to appreciate that, in order to subject the problematic metaphysical assumption of unity to the kind of scrutiny that is required, we need to represent it in the form of a hierarchy of assumptions, these assumptions asserting less and less as we go up the hierarchy, and thus becoming more and more likely to be true, and also becoming more nearly such that their truth is required for science to be possible at all: see Figure 2. As we descend the hierarchy of assumptions, they become increasingly substantial, and thus increasingly likely to be false. Criticism and attempted improvement need to be concentrated low down in the hierarchy, at levels 3 and 4 in Figure 2.

At level 7 in Figure 2 we have the assumption that the universe is such that we can acquire knowledge of our local circumstances sufficient to make life possible. If this assumption is false, we have had it, whatever we assume. Even though we have no good reason to hold this level 7 assumption is true, it can never hinder the pursuit of knowledge to accept the assumption as a part of our knowledge, and may well help this pursuit. At level 6 there is the more substantial assumption that the universe is such that we can make a discovery about it which enables us to improve our methods for the improvement of knowledge. The universe is such, in other words, that we can learn how to learn. At level 5 there is the even more substantial thesis that the universe is comprehensible in some way. There is a standard kind of explanation as to why phenomena occur as the do. It might be that they occur as a result of the will of God, or to fulfil a cosmic purpose, or to be in accordance with something like a computer programme, or to accord with a unified pattern of physical law. This conjecture exemplifies the level 5 thesis since it holds out the promise that, by modifying our ideas about how the universe is comprehensible to accord with those explanatory theories that meet with the most empirical success, we will be able progressively to improve our methods for discovering and accepting new theories. The level 4 thesis of physicalism has arisen in precisely this way. It asserts that the universe is such that all phenomena occur in accordance with a unified pattern of physical law. This assumption has proved to be astonishingly fruitful empirically, in that the whole enterprise of theoretical physics accords with it. Ever since Galileo, as physics has progressed, the totality of fundamental physical theory has become both (1) increasingly unified, and (2) increasingly vast in empirical scope, in that more and more phenomena are successfully predicted with increasing accuracy. At level 3 there is our best conjecture as to what specific kind of unified pattern of physical law is inherent in all phenomena. Here, we are almost bound to get things wrong, as the historical record indicates.

Associated with each metaphysical thesis, at levels 7 to 3, there are methods which require that theses and theories, lower down in the hierarchy, must be (as far as possible) compatible with the given thesis. At level 3, that thesis is to be accepted which best accords with the thesis at level 4 and, at the same time, accords best with the most empirically successful physical theories, at level 2. The hope is that, as a result of modifying the thesis at level 3 so that it accords better with the level 4 thesis, ideas for good new level 2 theories will emerge, new metaphysics leading to new physics. As physics advances, and theoretical knowledge at levels 1 and 2 improve, so too metaphysical conjectures at levels 3 and 4 may improve as well, this leading to an improvement in associated methods. Something like positive feedback can take place between improving knowledge and improving assumptions and associated methods - improving knowledge about how to improve knowledge, in other words. 


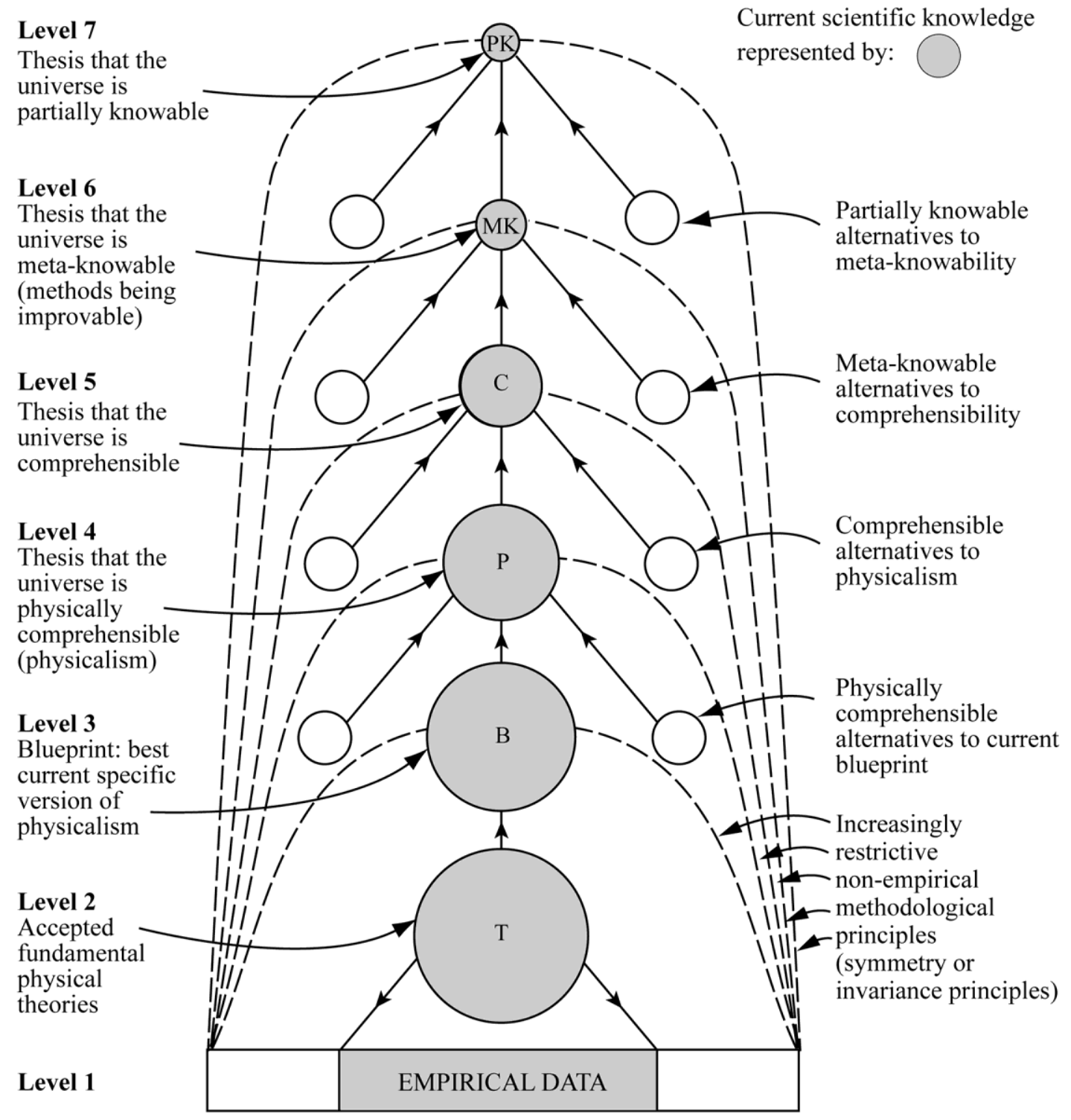

Figure 2: Aim-Oriented Empiricism

This process of positive feedback between improving knowledge, and improving methods for the improvement of knowledge, has actually gone on in science, ${ }^{17}$ but in a somewhat furtive, curtailed fashion, due to the general acceptance of standard empiricism and the failure of the scientific community to conceive of and adopt aim-oriented empiricism, my term for the hierarchical conception of scientific method depicted in Figure 2. ${ }^{18}$ The extraordinary success of physics is due to the somewhat constrained implementation of aimoriented empiricism - constrained as a result of the (mistaken) conviction of the physics community that they ought to implement standard empiricism. ${ }^{19}$

What I have said so far about problematic assumptions and methods can be reformulated to be about problematic aims and methods. The basic aim of physics is not truth, as standard empiricism assumes. It is rather truth presupposed to be unified or explanatory. Precisely because this aim is so profoundly problematic (we conjecture, but do not know, that the truth is explanatory), we need to represent this problematic aim in the form of a hierarchy of aims - aims becoming increasingly unproblematic as we ascend the hierarchy, and metaphysical assumptions implicit in the aims become increasingly lacking in specific content. In this 
way, we provide ourselves with a fixed framework of relatively unproblematic aims and associated methods (high up in the hierarchy), within which much more problematic aims and associated methods may be improved, in the light of which meet with empirical success and which do not, as we proceed with scientific research. Aims and methods evolve with evolving scientific knowledge.

This is the conception of scientific method, implicit in scientific practice since Galileo and Newton, that is responsible for the astonishing progress achieved by natural science over the centuries. ${ }^{20}$ It is this conception of the progress-achieving methods of science that the philosophes of the Enlightenment ought to have pounced upon, generalized, and applied to the task of making social progress towards an enlightened world. If they had done that, we might today live in a far more enlightened world than we do. Alas, right from the outset, the philosophes got the progress-achieving methods of science seriously wrong - as we still do today!

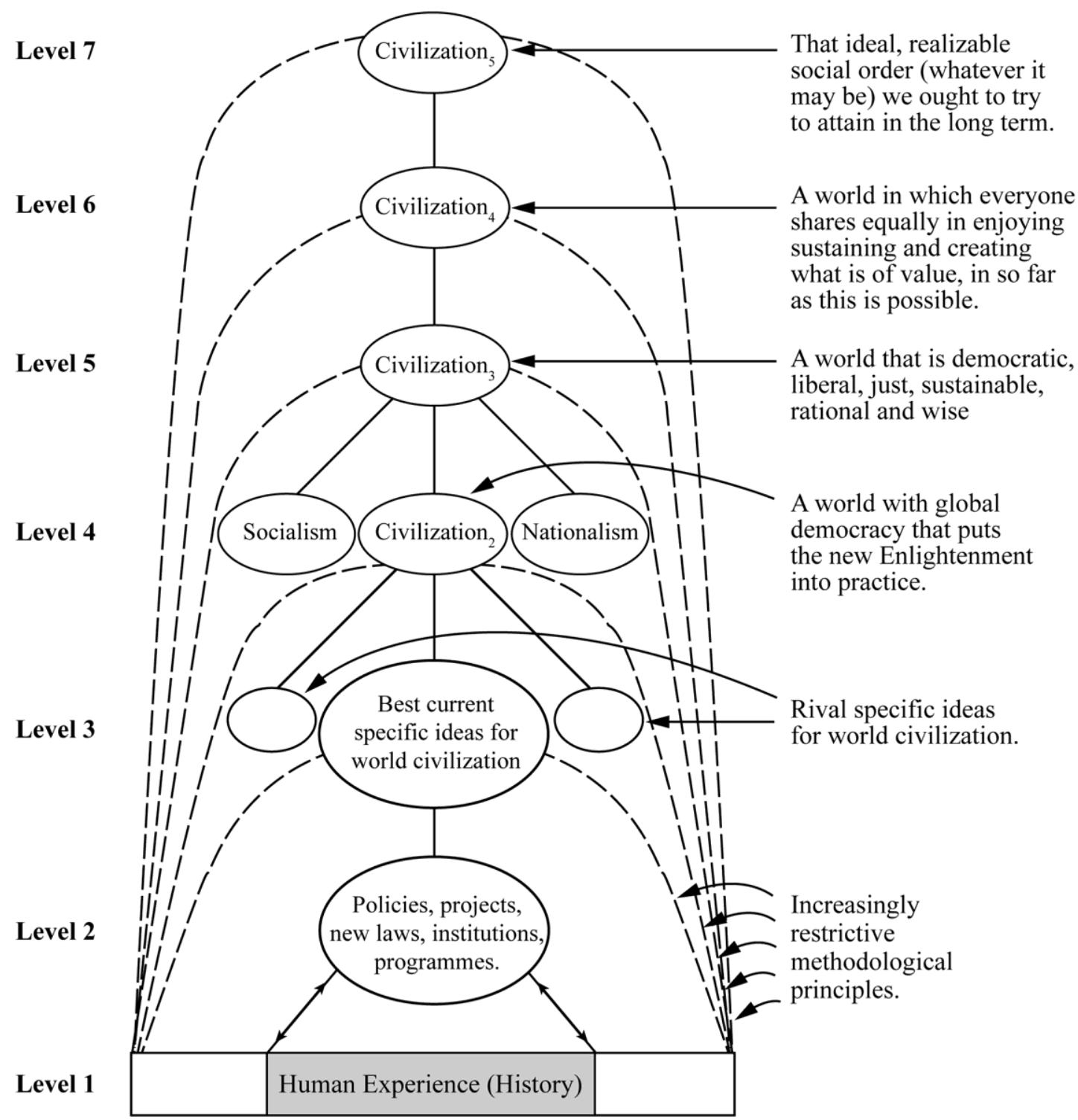

Figure 3: Aim-Oriented Rationality Applied to the Task of Making Progress Towards an Enlightened, Civilized World 
Step 2: Generalizing scientific method. Having failed to capture correctly the progressachieving methods of science, the philosophes naturally failed to generalize these methods correctly, so that they became fruitfully applicable, potentially, to any worthwhile human endeavour with problematic aims: politics, economics, the law, industry, agriculture, and above all the endeavour to make social progress towards an enlightened world. In order to generalize aim-oriented empiricism in the required way, we first need to interpret the metaphysical theses at levels 3 to 7 as aims; in each case, the aim of physics is to transform the metaphysical thesis into a testable, true, physical "theory of everything" (a theory able, in principle, to predict all physical phenomena). Next, this hierarchy of aims needs to be freed entirely from science to become aims of any worthwhile human endeavour with problematic aims, whatsoever it may be. At level 2, instead of theories there are human actions, actual and possible, and at level 1, instead of the results of scientific observation and experiment, there is human experience - what we enjoy and suffer as a result of what we do, the policies we pursue. Aim-oriented empiricism, generalized in this way, may be called aim-oriented rationality. It provides a framework for the assessment of actions, and proposals for actions, in terms of human experience, what we enjoy and suffer as a result of what we, or others, do. At the same time, it provides a framework for the progressive improvement of problematic aims, and associated methods, as we act, as we engage in our endeavour, whatever it may be. Aim-oriented rationality is designed to help us improve our aims, and the methods we employ in seeking to realize our aims, whatever it is we are doing: an individual person trying to resolve a quarrel with a friend; a police force, school, or political party, trying to improve the way they serve their community; a group of individuals attempting to alert their fellow citizens to the impending disasters of climate change. Figure 3 depicts aim-oriented rationality applied to the task of achieving civilization. ${ }^{21}$

The hope is that, as a result of employing the progress-achieving methods of aim-oriented rationality in personal and social life in this way, arrived at by generalizing the progressachieving methods of science, we will be able to get into personal and social life something of the astonishing success achieved by natural science.

Step 3: Applying generalized progress-achieving methods of science to social life. It is here, at this crucial third step of the Enlightenment programme, that the philosophes made their most disastrous mistake. Instead of applying generalized progress-achieving methods of science directly to social life to help humanity make social progress towards an enlightened world, the philosophes applied their conception of scientific method to the task of improving knowledge of the social world. They set about creating the social sciences in other words. Instead of developing social inquiry as social methodology, actively engaged in helping humanity pursue worthwhile but problematic aims in more rational ways, the philosophes made the dreadful blunder of developing social inquiry as social science: economics, psychology, sociology, anthropology, political science. And this dreadful blunder is still with us today. It was enthusiastically developed throughout the $19^{\text {th }}$ century by figures as diverse as J.S. Mill, Karl Marx, Max Weber, and others, as I have already mentioned, and was built into academia by the early $20^{\text {th }}$ century with the creation of departments and academic disciplines of the social sciences. It is this monumental blunder that is responsible for the gross, damaging, structural irrationality of academia today, for it is this blunder that is the historical source of the current domination of academia by knowledge-inquiry.

It is perhaps understandable that the philosophes, in the $18^{\text {th }}$ century, made the dreadful mistake of assuming that the first step we need to take to make social progress toward an enlightened world is to acquire knowledge of the social world. The prestige of the natural philosophy of Galileo, Kepler, Boyle and Newton was such that it would have seemed overwhelmingly obvious to the philosophes that, in order to achieve social progress, 
knowledge of the social world must first be acquired. Francis Bacon had emphasized just how vital it is to acquire knowledge of nature in order to alleviate human suffering and promote human welfare: all the more important, so the philosophes assumed, to acquire knowledge of ourselves, our human world, the laws of social development.

The philosophes can be forgiven their blunder. What is unforgivable is that this blunder is still inherent in academic inquiry today. And what makes the matter all the more unforgivable is that the blunder has been laid bare for all to see, in book after book, article after article, since the publication of my From Knowledge to Wisdom in $1984 .{ }^{22}$

But is it a blunder? Perhaps we do first need to acquire knowledge before rational action is possible? Perhaps knowledge-inquiry is exactly what academia ought to implement, it being entirely correct to give priority to the pursuit of knowledge before rational tackling of problems of living becomes possible.

I have six points to make in criticism of this suggestion.

First, even if the objection were valid, it would still be vital for a kind of inquiry designed to help us build a better world to include rational exploration of problems of living, and to ensure that this exploration guides priorities of scientific research (and is guided by the results of such research).

Second, the validity of the objection becomes dubious when we take into account the considerable success people met with in solving problems of living in a state of extreme ignorance, before the advent of science. We still today often arrive at solutions to problems of living in ignorance of relevant facts.

Third, the objection is not valid. In order to articulate problems of living and explore imaginatively and critically possible solutions (in accordance with Popper's conception of rationality: see note 11), we need to be able to act in the world, imagine possible actions, and share our imaginings with others: in so far as some common sense knowledge is implicit in all this, such knowledge is required to tackle rationally and successfully problems of living. But this does not mean that we must give intellectual priority to acquiring new relevant knowledge before we can be in a position to tackle rationally our problems of living.

Fourth, simply in order to have some idea of what kind of knowledge or know-how it is relevant for us to try to acquire, we must first have some provisional ideas as to what our problem of living is and what we might do to solve it. Articulating our problem of living and proposing and critically assessing possible solutions needs to be intellectually prior to acquiring relevant knowledge simply for this reason: we cannot know what new knowledge it is relevant for us to acquire until we have at least a preliminary idea as to what our problem of living is, and what we propose to do about it. A slight change in the way we construe our problem may lead to a drastic change in the kind of knowledge it is relevant to acquire: changing the way we construe problems of health, to include prevention of disease (and not just curing of disease) leads to a dramatic change in the kind of knowledge we need to acquire (importance of exercise, diet etc.). Including the importance of avoiding pollution in the problem of creating wealth by means of industrial development leads to the need to develop entirely new kinds of knowledge.

Fifth, relevant knowledge is often hard to acquire; it would be a disaster if we suspended life until it had been acquired. Knowledge of how our brains work is presumably highly relevant to all that we do but clearly, suspending rational tackling of problems of living until this relevant knowledge has been acquired would not be a sensible step to take. It would, in any case, make it impossible for us to acquire the relevant knowledge (since this requires scientists to act in doing research). Scientific research is itself a kind of action carried on in a state of relative ignorance.

Sixth, the capacity to act, to live, more or less successfully in the world, is more fundamental than (propositional) knowledge. Put in Rylean terms, 'knowing how' is more 
fundamental than 'knowing that' (Ryle, 1949, ch. II). All our knowledge is but a development of our capacity to act. Dissociated from life, from action, knowledge stored in libraries is just paper and ink, devoid of meaning. In this sense, problems of living are more fundamental than problems of knowledge (which are but an aspect of problems of living); giving intellectual priority to problems of living quite properly reflects this point. ${ }^{23}$

Almost all the grave global problems that threaten our future have arisen because we have failed to put something like aim-oriented rationality into practice in our political, economic, industrial, international life. We have failed to anticipate undesirable consequences of major new social endeavours, made possible by science and technology or, when such anticipations have been made, we have failed to act - to modify what we do - so as to avoid experiencing these undesirable consequences. We have failed to develop the social-political-economic muscle needed to perform such actions. We develop modern hygiene and medicine around the world but fail to make birth control freely available universally, to check rising populations. We develop agriculture but fail to modify how it develops when it becomes apparent we are destroying natural habitats, destroying wild life, and causing mass extinctions. We develop modern industry, power-production and transport, but fail respond adequately when we discover we are transforming our climate so that densely inhabited regions of the earth may become uninhabitable, mass migration will ensue, with wars a likely outcome. We develop nuclear weapons to increase our security, when in fact the mere existence of such weapons, ready for launching at the touch of a button, threatens the future of humanity. We develop the internet and social media, and fail to anticipate how they can subvert democracy. And when we do make this discovery, our efforts to change the way the internet and social media operate seem hopelessly inadequate. Again and again, enormous changes in the way we act, made possible by scientific and technological developments, have an admixture of good and bad outcomes. We fail to anticipate the bad outcomes. We may not even actively try to do so. When a few do succeed in such anticipations, initially they are ignored. When no longer ignored, there is a lamentable failure for those involved to act. All this amounts to a failure to put anything like aim-oriented rationality into social, institutional practice. Even worse, we have failed even to see just how profoundly important it is that this should be done. A proper, basic task of social inquiry and the humanities is to help humanity learn how aim-oriented rationality can be built into social and institutional life. Social inquiry and the humanities have failed to take up this task. They have not even conceived of their tasks in these terms. Even worse, academia makes no attempt to put aim-oriented rationality into practice as far as its own activities are concerned. Worse still, rationality is, in general, not even conceived of in these terms.

One outcome of getting into social and institutional life the kind of aim-evolving, hierarchical methodology indicated above, generalized from science, is that it becomes possible for us to develop and assess rival philosophies of life as a part of social life, somewhat as theories are developed and assessed within science. Such a hierarchical methodology provides a framework within which competing views about what our aims and methods in life should be - competing religious, political and moral views - may be cooperatively assessed and tested against broadly agreed, unspecific aims (high up in the hierarchy of aims) and the experience of personal and social life. There is the possibility of cooperatively and progressively improving such philosophies of life (views about what is of value in life and how it is to be achieved), much as theories are cooperatively and progressively improved in science. In science, ideally, theories are critically assessed with respect to each other, with respect to metaphysical ideas concerning the comprehensibility of the universe, and with respect to experience (observational and experimental results). In a somewhat analogous way, diverse philosophies of life may be critically assessed with respect to each other, with respect to relatively uncontroversial, agreed ideas about aims and what is of value, and with respect to 
experience - what we do, achieve, fail to achieve, enjoy and suffer - the aim being to improve philosophies of life (and more specific philosophies of more specific enterprises within life such as government, education or art) so that they offer greater help with the realization of what is of value in life.

This hierarchical methodology is especially relevant to the task of resolving conflicts about aims and ideals, as it helps disentangle agreement (high up in the hierarchy) and disagreement (more likely to be low down in the hierarchy).

Wisdom-inquiry, because of its greater rigour, has intellectual standards that are, in important respects, different from those of knowledge-inquiry. Whereas knowledge-inquiry demands that emotions and desires, values, human ideals and aspirations, philosophies of life be excluded from the intellectual domain of inquiry, wisdom-inquiry requires that they be included. In order to discover what is of value in life, it is essential that we attend to our feelings and desires. But not everything we desire is desirable, and not everything that feels good is good. Feelings, desires, and values need to be subjected to critical scrutiny. And of course feelings, desires and values must not be permitted to influence judgements of factual truth and falsity. Wisdom-inquiry embodies a synthesis of traditional rationalism and romanticism. It includes elements from both, and it improves on both. It incorporates romantic ideals of integrity, having to do with motivational and emotional honesty, honesty about desires and aims; and at the same time, it incorporates traditional rationalist ideals of integrity, having to do with respect for objective fact, knowledge, and valid argument. Traditional rationalism takes its inspiration from science and method; romanticism takes its inspiration from art, from imagination, and from passion. Wisdom-inquiry holds art to have a fundamental rational role in inquiry, in revealing what is of value, and unmasking false values; but science, too, is of fundamental importance. What we need, for wisdom, is an interplay of sceptical rationality and emotion, an interplay of mind and heart, so that we may develop mindful hearts and heartfelt minds. It is time we healed the great rift in our culture, so graphically depicted by Snow (1969).

\section{Cultural Implications of Wisdom-Inquiry}

Wisdom-inquiry does not just do better justice to the social or practical dimension of inquiry than knowledge-inquiry; it does better justice to the "intellectual" or "cultural" aspects as well.

From the standpoint of the intellectual or cultural aspect of inquiry, what really matters is the desire that people have to see, to know, to understand, the passionate curiosity that individuals have about aspects of the world, and the knowledge and understanding that people acquire and share as a result of actively following up their curiosity. An important task for academic thought in universities is to encourage non-professional thought to flourish outside universities. As Einstein once remarked, "Knowledge exists in two forms - lifeless, stored in books, and alive in the consciousness of men. The second form of existence is after all the essential one; the first, indispensable as it may be, occupies only an inferior position." (Einstein, 1973, p. 80).

Wisdom-inquiry is designed to promote passionate curiosity in a number of ways. It does so as a result of holding thought, at its most fundamental, to be the personal thinking we engage in as we live. It does so by recognizing that acquiring knowledge and understanding involves articulating and solving personal problems that one encounters in seeking to know and understand. It does so by recognizing that passion, emotion and desire, have a rational role to play in inquiry, disinterested research being a myth. Again, as Einstein has put it "The most beautiful experience we can have is the mysterious. It is the fundamental emotion which stands at the cradle of true art and true science. Whoever does not know it and can no 
longer wonder, no longer marvel, is as good as dead, and his eyes are dimmed." (Einstein, 1973, p. 11).

Knowledge-inquiry, by contrast, all too often fails to nourish "the holy curiosity of inquiry" (Einstein, 1949, p. 17), and may even crush it out altogether. Knowledge-inquiry gives no rational role to emotion and desire; passionate curiosity, a sense of mystery, of wonder, have no place, officially, within the rational pursuit of knowledge. The intellectual domain becomes impersonal and split off from personal feelings and desires; it is difficult for "holy curiosity" to flourish in such circumstances. Knowledge-inquiry hardly encourages the view that inquiry at its most fundamental is the thinking that goes on as a part of life; on the contrary, it upholds the idea that fundamental research is highly esoteric, conducted by physicists in contexts remote from ordinary life. Even though the aim of inquiry may, officially, be human knowledge, the personal and social dimension of this is all too easily lost sight of, and progress in knowledge is conceived of in impersonal terms, stored lifelessly in books and journals. Rare is it for popular books on science to take seriously the task of exploring the fundamental problems of a science in as accessible, non-technical and intellectually responsible a way as possible. ${ }^{24}$ Such work is not highly regarded by knowledge-inquiry, as it does not contribute to "expert knowledge". The failure of knowledge-inquiry to take seriously the highly problematic nature of the aims of inquiry leads to insensitivity as to what aims are being pursued, to a kind of institutional hypocrisy. Officially, knowledge is being sought "for its own sake", but actually the goal may be immortality, fame, the flourishing of one's career or research group, as the existence of bitter priority disputes in science indicates. Education suffers. Science students are taught a mass of established scientific knowledge but may not be informed of the problems which gave rise to this knowledge, the problems which scientists grappled with in creating the knowledge. Even more rarely are students encouraged themselves to grapple with such problems. And rare, too, is it for students to be encouraged to articulate their own problems of understanding that must, inevitably, arise in absorbing all this information, or to articulate their instinctive criticisms of the received body of knowledge. All this tends to reduce education to a kind of intellectual indoctrination and serves to kill "holy curiosity". ${ }^{25}$ Officially, courses in universities divide up into those that are vocational, like engineering, medicine and law, and those that are purely educational, like physics, philosophy or history. What is not noticed, again through insensitivity to problematic aims, is that the supposedly purely educational are actually vocational as well: the student is being trained to be an academic physicist, philosopher or historian, even though only a minute percentage of the students will go on to become academics. Real education, which must be open-ended, and without any predetermined goal, rarely exists in universities, and yet few people notice. These considerations are developed further in Maxwell (1976; 1980; 1984; 2004; 2014b; 2017b.)

In order to enhance our understanding of persons as beings of value, potentially and actually, we need to understand them empathetically, by putting ourselves imaginatively into their shoes, and experiencing, in imagination, what they feel, think, desire, fear, plan, see, love and hate. For wisdom-inquiry, this kind of empathic understanding is rational and intellectually fundamental. Articulating problems of living, and proposing and assessing possible solutions is, we have seen, the fundamental intellectual activity of wisdom-inquiry. But it is just this that we need to do to acquire empathic understanding. Social inquiry, in tackling problems of living, is also promoting empathic understanding of people. Empathic understanding is essential to wisdom. Elsewhere I have argued, indeed, that empathic understanding plays an essential role in the evolution of consciousness. It is required for cooperative action, and even for science. For a fuller exposition of such an account of empathic understanding, see Maxwell (1984, pp. 171-189 and ch. 10; and 2001, chs. 5-7 and 9). 
With knowledge-inquiry, empathic understanding hardly satisfies basic requirements for being an intellectually legitimate kind of explanation and understanding (Maxwell, 1984, pp. 183-185). It has the status merely of "folk psychology", on a par with "folk physics."

Wisdom-inquiry is both more rigorous, and better able to serve the best interests of humanity, than knowledge-inquiry. It does better justice to both aspects of inquiry: the intellectual or cultural aspect, and the humanitarian or practical aspect. We urgently need to bring about an intellectual/institutional revolution in academia in universities around the world. We need a change of paradigm in the whole conception of what constitutes intellectually worthwhile inquiry devoted to the best interests of humanity.

\section{Conclusion}

If $60 \%$ of humanity acquired wisdom, we might be able to solve the grave global problems that confront us. But how is this crucial, widespread wisdom, personal and social, to be acquired in the first place? It could be acquired if academia corrected its current, glaring, structural, rationality defects, corrected the three grave blunders we have inherited from the Enlightenment, and transformed knowledge-inquiry so that it becomes wisdom-inquiry. Wisdom-inquiry is specifically designed to help humanity acquire wisdom - acquire the capacity, active endeavour and desire to realize what is of value in life, for one's own person and for others. If academia had taken up the argument of From Knowledge to Wisdom when it was first published in 1984, and had begun to make the changes required to put wisdominquiry into academic practice, we might now, in democratic nations at least, have universities that put wisdom-inquiry into practice, and we might already be on the way to acquiring the essential $60 \%$ of wise citizens. But this has not happened. The log-jam that prevents the world from solving its global problems is, fundamentally, the stubborn, irrational prejudices of academics.

Here, to conclude, is a list of 23 structural changes that need to be made to academia as it is at present constituted, by and large dominated by knowledge-inquiry, if we are to have what we so urgently need: institutions of learning rationally organized and devoted to helping us solve problems of living in increasingly cooperative ways, so that we may make social progress towards a good, civilized, enlightened world.

1. There needs to be a radical change in the basic aim of academic inquiry. Knowledgeinquiry has two distinct aims: the intellectual one of acquiring knowledge, and the social or humanitarian one of helping to promote human welfare by intellectual, technological and educational means. Wisdom-inquiry fuses these two aims into one: the intellectual/humanitarian aim of seeking and promoting personal and social wisdom as characterized above.

2. There needs to be a change in the nature of academic problems, so that problems of living are included, as well as problems of knowledge - the former being treated as intellectually more fundamental than the latter.

3. There needs to be a change in the nature of academic ideas, so that proposals for action are included as well as claims to knowledge - the former, again, being treated as intellectually more fundamental than the latter.

4. There needs to be a change in what constitutes intellectual progress, so that progress-inideas-relevant-to-achieving-a-more-civilized-world is included as well as progress in knowledge, the former being indeed intellectually fundamental.

5. There needs to be a change in the idea as to where inquiry, at its most fundamental, is located. It is not esoteric theoretical physics, but rather the thinking we engage in as we seek to achieve what is of value in life. Academic thought is a (vital) adjunct to what really matters, personal, and social thought active in life. 
6. There needs to be a dramatic change in the nature of social inquiry (reflecting points 1 to 5). Economics, politics, sociology, and so on, are not, fundamentally, sciences, and do not, fundamentally, have the task of improving knowledge about social phenomena. Instead, their task is threefold. First, it is to articulate problems of living, and propose and critically assess possible solutions, possible actions or policies, from the standpoint of their capacity, if implemented, to promote wiser ways of living. Second, it is to promote such cooperatively rational tackling of problems of living throughout the social world. And third, at a more basic and long-term level, it is to help build the hierarchical structure of aims and methods of aim-oriented rationality into personal, institutional and global life, thus creating frameworks within which progressive improvement of personal and social life aims-and-methods becomes possible. These three tasks are undertaken in order to promote cooperative tackling of problems of living - but also in order to enhance empathic or "personalistic" understanding between people as something of value in its own right. Acquiring knowledge of social phenomena is a vital but subordinate activity, engaged in to facilitate the above three fundamental pursuits.

7. Natural science needs to change, so that it includes at least three levels of discussion: evidence, theory, and research aims. Discussion of aims needs to bring together scientific, metaphysical, and evaluative consideration in an attempt to discover the most desirable and realizable research aims. It needs to influence, and be influenced by, exploration of problems of living undertaken by social inquiry and the humanities, and the public.

8. There needs to be a dramatic change in the relationship between social inquiry and natural science, so that social inquiry becomes intellectually more fundamental from the standpoint of tackling problems of living, promoting wisdom. Social inquiry influences choice of research aims for the natural and technological sciences, and is, of course, in turn influenced by the results of such research. (Social inquiry also, of course, conducts empirical research, in order to improve our understanding of what our problems of living are and in order to assess policy ideas whenever possible.)

9. The current emphasis on specialized research needs to change so that sustained discussion and tackling of broad, global problems that cut across academic specialities is included, both influencing and being influenced by, specialized research.

10. Academia needs to include sustained imaginative and critical exploration of possible futures, for each country, and for humanity as a whole, policy and research implications being discussed as well.

11. The way in which academic inquiry as a whole is related to the rest of the human world needs to change dramatically. Instead of being intellectually dissociated from the rest of society, academic inquiry needs to be communicating with, learning from, teaching and arguing with the rest of society - in such a way as to promote cooperative rationality and social wisdom. Academia needs to have just sufficient power to retain its independence from the pressures of government, industry, the military, and public opinion, but no more. Academia becomes a kind of civil service for the public, doing openly and independently what actual civil services are supposed to do in secret for governments.

12. There needs to be a change in the role that political and religious ideas, works of art, expressions of feelings, desires and values have within rational inquiry. Instead of being excluded, they need to be explicitly included and critically assessed, as possible indications and revelations of what is of value, and as unmasking of fraudulent values in satire and parody, vital ingredients of wisdom.

13. There need to be changes in education so that, for example, seminars devoted to the cooperative, imaginative, and critical discussion of problems of living are at the heart of all education from five-year-olds onwards. Politics, which cannot be taught by knowledge- 
inquiry, becomes central to wisdom-inquiry, political creeds and actions being subjected to imaginative and critical scrutiny.

14. There need to be changes in the aims, priorities, and character of pure science and scholarship, so that it is the curiosity, the seeing and searching, the knowing and understanding of individual persons that ultimately matters, the more impersonal, esoteric, purely intellectual aspects of science and scholarship being means to this end. Social inquiry needs to give intellectual priority to helping empathic understanding between people to flourish (as indicated in 6 above).

15. There need to be changes in the way mathematics is understood, pursued, and taught. Mathematics is not a branch of knowledge at all. Rather, it is concerned with exploring problematic possibilities, and to develop, systematize, and unify problem-solving methods. ${ }^{26}$

16. Literature needs to be put close to the heart of rational inquiry, in that it explores imaginatively our most profound problems of living and aids personalistic understanding in life by enhancing our ability to enter imaginatively into the problems and lives of others.

17 Philosophy needs to change so that it ceases to be just another specialized discipline and becomes instead that aspect of inquiry as a whole that is concerned with our most general and fundamental problems - those problems that cut across all disciplinary boundaries. Philosophy needs to become again what it was for Socrates: the attempt to devote reason to the growth of wisdom in life.

18 Academic contributions need to be written in as simple, lucid, jargon-free a way as possible, so that academic work is as accessible as possible across specialities and to nonacademics.

19. There needs to be a change in views about what constitute academic contributions, so that publications which promote (or have the potential to promote) public understanding as to what our problems of living are and what we need to do about them are included, in addition to contributions addressed primarily to the academic community.

20. Every university needs to create a seminar or symposium devoted to the sustained discussion of fundamental problems that cut across all conventional academic boundaries, global problems of living being included as well as global problems of knowledge and understanding.

The above changes all come from my "from knowledge to wisdom" argument spelled out above, and in detail elsewhere (see note 6). The following three institutional innovations do not follow from that argument but, if implemented, would help wisdom-inquiry to flourish.

21. Natural science needs to create committees, in the public eye, and staffed by scientists and non-scientists alike, concerned with highlighting and discussing failures of the priorities of research to respond to the interests of those whose needs are the greatest - the poor of the earth - as a result of the inevitable tendency of research priorities to reflect the interests of those who pay for science, and the interests of scientists themselves.

22. Every national university system needs to include a national shadow government, seeking to do, virtually, free of the constraints of power, what the actual national government ought to be doing. The hope would be that virtual and actual governments would learn from each other.

23. The world's universities need to include a virtual world government which seeks to do what an actual elected world government ought to do, if it existed. The virtual world government would also have the task of working out how an actual democratically elected world government might be created. 


\section{Conclusion}

Two great problems of learning confront humanity: learning about the nature of the universe and about ourselves and other living things as a part of the universe, and learning how to become civilized. The first problem was solved, in essence, in the 17th century, with the creation of modern science. But the second problem has not yet been solved. Solving the first problem without also solving the second puts us in a situation of great danger. All our current global problems have arisen as a result. What we need to do, in response to this unprecedented crisis, is learn from our solution to the first problem how to solve the second. This was the basic idea of the 18th century Enlightenment. Unfortunately, in carrying out this programme, the Enlightenment made three blunders, and it is this defective version of the Enlightenment programme, inherited from the past, that is still built into the institutional/intellectual structure of academic inquiry in the 21 st century. In order to solve the second great problem of learning we need to correct the three blunders of the traditional Enlightenment. This involves changing the nature of social inquiry, so that social science becomes social methodology or social philosophy, concerned to help us build into social life the progress-achieving methods of aim-oriented rationality, arrived at by generalizing the progress-achieving methods of science. It also involves, more generally, bringing about a revolution in the nature of academic inquiry as a whole, so that it takes up its proper task of helping humanity learn how to become wiser by increasingly cooperatively rational means. The scientific task of improving knowledge and understanding of nature becomes a part of the broader task of improving global wisdom. The outcome would be what we so urgently need: a kind of inquiry rationally designed and devoted to helping us make progress towards a genuinely civilized world. We would succeed in doing what the Enlightenment tried but failed to do: learn from scientific progress how to go about making social progress towards as good a world as possible.

\section{References}

Einstein, A., 1949, "Autobiographical Notes", in P. A. Schilpp, ed. Albert Einstein:

Philosopher-Scientist, Open Court, Illinois, pp. 3-94. 1973, Ideas and Opinions, Souvenir Press, London.

Gay, P., 1973, The Enlightenment: An Interpretation, Wildwood House, London.

Israel, J.I., 2013, Democratic Enlightenment, Oxford University Press, Oxford.

Maxwell, N., 1974, The Rationality of Scientific Discovery, Philosophy of Science 41, pp. 12353 and 247-95.

, 1976, What's Wrong with Science? Towards a People's Rational Science of Delight and Compassion, Bran's Head Books, Hayes, UK.

, 1980, Science, Reason, Knowledge and Wisdom: A Critique of Specialism, Inquiry 23, pp. 19-81.

, 1984, From Knowledge to Wisdom, Blackwell, Oxford ( $2^{\text {nd }}$ revised and extended edition, 2007, Pentire Press, London).

, 1991, How Can We Build a Better World? In Einheit der Wissenschaften:

Internationales Kolloquium der Akademie der Wissenschaften zu Berlin, 25-27 June 1990. J. Mittelstrass (editor), Walter de Gruyter, Berlin and New York, pp. 388-427.

, 1992, What Kind of Inquiry Can Best Help Us Create a Good World?, Science,

Technology and Human Values 17, 1992, pp. 205-27.

1993, Induction and Scientific Realism: Einstein versus van Fraassen, British Journal for the Philosophy of Science, vol. 44, pp. 61-79,

81-101 and 275-305.

1994, Towards a New Enlightenment: What the task of Creating Civilization has to

learn from the Success of Modern Science, in Academic Community: Discourse or

Discord?, edited by R. Barnett, Jessica Kingsley, pp. 86-105. 
1998, The Comprehensibility of the Universe, Clarendon Press, Oxford.

1999, Are there Objective Values?, The Dalhousie Review, 79 (3), pp. 301-317.

2000, Can Humanity Learn to become Civilized? The Crisis of Science without

Civilization, Journal of Applied Philosophy 17, 2000, pp. 29-44.

,2001, The Human World in the Physical Universe: Consciousness, Free Will and

Evolution, Rowman and Littlefield, Lanham, Maryland.

2003, Science, Knowledge, Wisdom and the Public Good, Scientists for Global

Responsibility Newsletter 26, February 2003, pp. 7-9.

, 2004, Is Science Neurotic?, Imperial College Press, London.

, 2005a, A Revolution for Science and the Humanities: From Knowledge to Wisdom,

Dialogue and Universalism, vol. XV, no. 1-2, pp. 29-57.

, 2005b, Philosophy Seminars for Five-Year-Olds, Learning for Democracy: An

International Journal of Thought and Practice, vol. 1, no. 2, pp. 71-7.

, 2007, From Knowledge to Wisdom: The Need for an Academic Revolution, London

Review of Education, vol. 5, no. 2, pp. 97-115.

2008, Are Philosophers Responsible for Global Warming?, Philosophy Now, issue

65 , pp. $12-13$.

2009, How Can Life of Value Best Flourish in the Real World?, in Science and the

Pursuit of Wisdom: Studies in the Philosophy of Nicholas Maxwell, edited by Leemon

McHenry, Ontos Verlag, Frankfurt, 2009, pp. 1-56.

, 2010, Wisdom Mathematics, Friends of Wisdom Newsletter, No. 6, pp. 1-6;

http://www.knowledgetowisdom.org/Newsletter\%206.pdf .

, 2011, We Need an Academic Revolution, Oxford Magazine, No. 309, pp. 15-18.

,2012a, Arguing for Wisdom in the University: An Intellectual Autobiography,

Philosophia , 40 (4) pp. 663-704.

,2012b, Creating a Better World: Towards the University of Wisdom, in R. Barnett,

ed., The Future University: Ideas and Possibilities, Routledge, New York, 2012, pp. 123-138.

, 2012c, How Universities Can Help Humanity Learn How to Resolve the Crises of Our

Times - From Knowledge to Wisdom: The University College London Experience,

Handbook on the Knowledge Economy, vol. 2, ed. G. Heam, T. Katlelle and D. Rooney,

Edward Elgar, Cheltenham, pp. 158-179.

, 2012d, Our Global Problems And What We Need To Do About Them, in Tandy, C.,

and J. Lee, ed., Death and Anti-Death Anthology, vol. 10: Ten Years After John Rawls

(1921-2002), Ch. 7, pp. 131-174, Ria University Press, Palo Alto, California.

2013, Knowledge or Wisdom?, The Philosophers' Magazine, issue 62, 3rd

quarter 2013, pp. 17-18.

2014a, How Universities Can Help Create a Wiser World: The Urgent Need for an

Academic Revolution, Imprint Academic, Exeter.

, 2014b, Global Philosophy: What Philosophy Ought to Be, Imprint Academic, Exeter.

, 2015, What's Wrong With Aim-Oriented Empiricism?, Acta Baltica Historiae et

Philosophiae Scientiarum, vol. 3, no. 2, 5-31.

, 2016, Can Scientific Method Help Us Create a Wiser World?, in N. Dalal, A. Intezari

and M. Heitz, ed., Practical Wisdom in the Age of Technology: Insights, Issues and

Questions for a New Millennium, Routledge, London, ch. 11, pp. 147-161.

,2017a, Understanding Scientific Progress, Paragon House, Saint Paul, Minnesota.

, 2017b, In Praise of Natural Philosophy: A Revolution for Thought and Life, McGill-

Queen's University Press, Montreal.

, 2017c, Karl Popper, Science and Enlightenment, UCL Press, London.

, 2018a, We Need Progress in Ideas about how to achieve Progress, Metascience, vol.

27, issue 2, pp. 347-350. 
,2018b, The Scandal of the Irrationality of Academia, Philosophy and Theory in Higher

Education, special issue on "The Anthropocene and Higher Education", Autumn, 2018.

2018c, Do We Need an Academic Revolution to Create a Wiser World?, in R. Barnett

$\&$ M. A. Peters, eds., The Idea of the University: Volume 2:Contemporary Perspectives, Peter Lang, New York.

,2019, Science and Enlightenment: Two Great Problems of Learning, Springer, Cham, Switzerland.

Newton, I., 1962, Principia, translated by A. Motte and revised by F. Cajori, University of

California Press, Berkeley (first published 1687).

Penrose, R., 2004, The Road to Reality, Jonathan Cape, London.

Piketty, T., 2014, Capital in the Twenty-First Century, tr. A. Goldhammer, Harvard University

Press, Cambridge, Mass.

Pinker, S., 2018, Enlightenment NOW: The Case for Reason, Science, Humanism and Progress, Allen Lane, London.

Polya, G., 1957, How to Solve It, Anchor Books, New York.

Ryle, G., 1949, The Concept of Mind, Hutchinson, London.

Snow, C.P., 1969, The Two Cultures and a Second Look, Cambridge University Press, London. Sternberg, R.J., 2016, What Universities Can Be, Cornell University Press, New York.

Wilkinson, R. and K. Pickett, 2010, The Spirit Level, Penguin Books, London.

\section{Notes}

\footnotetext{
${ }^{1}$ See Pinker (2018) for a much more optimistic account of our future, and see Maxwell (2018) for a decisive criticism. Steven Pinker fails to appreciate that he invokes a profoundly defective and damaging version of the Enlightenment programme, one which is, in part, responsible for the genesis of the global problems that confront us - a point that I will highlight as we proceed.

${ }^{2}$ See www.theguardian.com/environment/2014/sep/18/world-population-new-study-11bn2100 , accessed 12 April 2015.

${ }^{3}$ See Maxwell (1984, ch. 10) for an account of what is of value in existence. See also Maxwell (1999) for an exposition of the argument that what is of value is both objective and conjectural in character.

${ }^{4}$ I characterized wisdom in this way so that wisdom, so construed, could be taken to be the proper, basic intellectual and social aim of academic inquiry. I have argued subsequently, however, that this is indeed an acceptable way to construe wisdom; it accommodates most more specific interpretations of wisdom that have been put forward: see Maxwell (2013).

${ }^{5}$ See https://en.wikipedia.org/wiki/Democracy_Index\#Democracy_Index by country_(2017).

${ }^{6}$ For books expounding the argument see Maxwell (1976; 1984; 2004; 2014a; 2014b; 2016; 2017a; 2017b; $2017 \mathrm{c})$. For articles summarizing the argument in a variety of ways see Maxwell $(1980 ; 1991 ; 1992 ; 1994$; 2000; 2003; 2005a-b; 2007; 2008; 2009; 2011; 2012a-d; 2013; 2016; 2018b-c).

${ }^{7}$ See Maxwell $\left(1984\right.$, ch. 6; and especially $2^{\text {nd }}$ ed., 2007, ch. 6) for data that establish the extent to which knowledge-inquiry dominates academia, in 1983, and in 2006. See also Maxwell (2019, ch. 6).

${ }^{8}$ For a detailed discussion that establishes the damaging irrationality of knowledge-inquiry, see Maxwell (1984 or $2^{\text {nd }}$ ed., 2007, ch. 3). See also Maxwell (2004; 2014a; 2017a; 2017b).

${ }^{9}$ For a brilliant account of rational problem-solving see Polya (1957).

${ }^{10}$ See Maxwell (1984, pp. 67-76) for more details concerning rational problem-solving. The key to solving a problem of living may come, not from (1) articulating the problem, and (2) proposing and critically assessing solutions, but from the solution to some apparently unrelated specialized problem, solved by means of rule (3) as when solutions to problems of pure research are discovered to have unexpected practical applications. That involves the implementation of rule (3). It does not, of course, go against the claim that we need to implement (1) to (4) to be rational.

${ }^{11}$ The first two of these rules of rational problem-solving are stressed by Karl Popper. He asserts, for example, "the one method of all rational discussion ... is that of stating one's problem clearly and of examining its various proposed solutions critically": Popper (1957, p. 16). Popper was, however, too adverse to specialization to include rule (3) as a basic rule of rational problem-solving. He did not appreciate that the evils of specialization can be counteracted by the implementation of rule (4).
} 


\footnotetext{
${ }^{12}$ I have not found the basic creed of the Enlightenment stated explicitly in this way; nevertheless, this is what the Enlightenment at its best, especially the French Enlightenment, amounted to. For two accounts of the Enlightenment along these lines, see Gay (1973); Israel (2013).

${ }^{13}$ In his Principia, Newton claimed: "In [natural] philosophy particular propositions are inferred from the phenomena, and afterwards rendered general by induction. Thus it was that ... the laws of motion and of gravitation, were discovered" Newton (1962, p. 547).

${ }^{14}$ For evidence that scientists and philosophers do take standard empiricism for granted see Maxwell (1998, pp. 38-45).

${ }^{15}$ For detailed expositions of this account of theory unity, improving in some respects as the years go by, see Maxwell (1998, chs. 3 and 4; 2004, appendix, section 2; 1984, $2^{\text {nd }}$ ed., 2007; 2017a, ch. 5).

${ }^{16}$ For much more detailed expositions of this crucial argument refuting standard empiricism, see Maxwell (1974; 1984, ch. 9; 1998, ch. 2; 2004, chs. 1 and 2; 2015; 2017a; 2017b).

${ }^{17}$ It is a platitude that this goes on at the experimental level. New knowledge leads to the development of new methods - new instruments, for example, such as the telescope or particle collider - which in turn lead to new knowledge. Because of the pernicious influence of standard empiricism, it is less widely appreciated that it goes on at the theoretical level as well (just as aim-oriented empiricism says it should). A classic case in point is the way Einstein's special theory of relativity becomes a methodological principle (an acceptable theory must be Lorentz invariant) which in turn contributes to the discovery and acceptance of major new physical theories, such as quantum electrodynamics and quantum chromodynamics.

${ }^{18}$ For much more detailed expositions of, and arguments for, aim-oriented empiricism, that have been progressively improved over the years, see works referred to in note 16 .

${ }^{19}$ See Maxwell (1993, pp. ${ }^{275-305}$ ) for an account of Einstein's exploitation of aim-oriented empiricism in discovering special and general relativity. See Maxwell (2017b, ch. 5) for an account of how physics would have met with even greater success if it had implemented aim-oriented empiricism explicitly over the centuries, undistracted by standard empiricism.

${ }^{20}$ For a discussion of this issue see especially Maxwell (2017b, especially chs. 1, 2, and 5).

${ }^{21}$ For much more detailed expositions of, and arguments for, aim-oriented rationality, see Maxwell (1984 and $2^{\text {nd }}$ ed., 2007, chs. 5 and 7 to $11 ; 2004 ; 2014 a ; 2019$ ).

${ }^{22}$ See works referred to in note 6. And see too Sternberg (2016).

${ }^{23}$ For a development of this point, see Maxwell (1984, pp. 174-181).

${ }^{24}$ A relatively recent, remarkable exception is Penrose (2004).

${ }^{25}$ I might add that the hierarchical conception of science indicated here does better justice to the scientific quest for understanding than does orthodox standard empiricist views: see Maxwell (1998, chs. 4 and $8 ; 2004$, ch. $2 ; 2017 b$, ch. 5).

${ }^{26}$ See Maxwell (2010).
} 